\title{
A Comparative Study of Predictive Current Control Schemes for a Permanent Magnet Synchronous Machine Drive
}

\author{
Florent Morel Member, IEEE, Xuefang Lin Shi, Jean-Marie Rétif, Bruno Allard Senior Member, IEEE, \\ Cyril Buttay Member, IEEE
}

\begin{abstract}
This paper presents a comparative study of three Predictive Current Control (PCC) schemes for Permanent Magnet Synchronous Machines (PMSM) drives. The first control scheme predicts the future evolution of the currents for each possible configuration of the inverter legs. Then the switching state which minimizes a given cost function is selected and applied during the next sampling time. The second control scheme uses a modulator to apply two configurations of the inverter legs during a computation period. Among these configurations, one leads to null voltages. The duration of the other configuration is calculated in order to minimize the distance between the obtained state vector and the desired one. The third control scheme uses a model of the PMSM in order to predict the stator voltages which allows to reach the desired currents after one modulation period. An algebraic method is presented to compute the duty cycle of each leg of the inverter in a direct manner. These control schemes are detailed and tested using the same switching frequency on the same test-bench (1.6kW PMSM drive). A simulation study is performed in order to compare sensitivity to parameters of each control schemes. Experiments confirm the simulation results.
\end{abstract}

Index Terms-Predictive Control, Current Control, Permanent Magnet Synchronous Machine, Pulse Width Modulation, Robustness

\section{INTRODUCTION}

Inverter-fed AC-machines are widely used in industrial applications. In particular, to achieve fast torque responses and high-performance operation, Permanent Magnet Synchronous Machines (PMSM) are often used together with high performance current controls. Many studies have been conducted about the development of such algorithms. Among them, methods called Predictive Current Control (PCC) show very good performances compared to classical methods such as Vector Control or Direct Torque Control (DTC). The main objectives of the PCC are to control instantaneous stator currents with high accuracy in a transient interval that is as short as possible [1]. It can provide high dynamic performance and low current harmonic to ensure the quality of the torque and speed control [2].

Copyright (C) 2009 IEEE. Personal use of this material is permitted. However, permission to use this material for any other purposes must be obtained from the IEEE by sending a request to pubs-permissions@ieee.org.

The authors are with AMPERE lab, UMR CNRS 5005, Lyon, France.

Florent Morel is with the École Centrale, Bât H9 - 36 avenue Guy de Collongue - 69134 Ecully Cedex - France. email : florent.morele ec-lyon.fr

Xuefang Lin-Shi, Jean-Marie Rétif, Bruno Allard and Cyril Buttay are with the Insa Lyon - Building Léonard de Vinci, 21 avenue Jean Capelle, 69621 VILLEURBANNE cedex, France.
Predictive current controls can be separated into (at least) three classes shortly introduced in the following sections.

\section{A. Direct Predictive Control}

The first class consists in predicting the future value of the load currents for all the voltage vectors that the power converter can generate. Then the configuration of the power converter which minimizes a cost function is selected. So one and only one configuration is selected for application during the following sampling period. This approach is a direct approach since the control variable is directly the inverter switching states; it is then noted Direct Predictive Control (DPC) in this paper. It is noted finite control set model predictive control in [3].

In the field of power converters, control schemes included in this class has been firstly introduced by Rodriguez et al. in 2004 [4], [5]. Since, such control schemes have been presented with various power converters (e.g. a three-phase two-level inverter [6] or a three-phase neutral-point-clamped inverter [7]) and with various machines (e.g. a doubly-fed induction machine [8]). In [9] different DPC are reported not only for the control of the current but also for the control of the power and for the control of the flux and the torque of an induction machine. The FPGA implementation of a DPC for a PMSM fed by voltage source inverter is detailed in [10].

It is worth noting that this control scheme is quite different from the Direct Torque Control (DTC) [11]. The sole common feature is that both algorithms directly select one and only one configuration of the inverter per computing occurrence. Indeed, with the DTC, the applied configuration is selected according to a table that is the result of a heuristic approach. There is no prediction of the future possible load currents. Furthermore, DTC makes use of hysteresis controllers, which lead to a variable computation frequency and a variable switching frequency. When the difference between measured values and reference values becomes higher than a threshold, DTC selects a configuration in order to reduce this error and maintains this configuration up to the error overtakes again the threshold. In this case, long computation steps result in torque and flux exceeding the hysteresis bands. In the opposite, with DPC, a configuration is selected in order to minimize errors after the following computing period. With this approach the controller acts before errors occur. It has been shown that DPC offers better performances than DTC when implemented in the same hardware [12]. 
A variation of DPC has been presented in [13] for a passive load and in [14] for an induction machine. It defines an active configuration as a configuration that lead to non-null voltages. The algorithm consists in choosing an active configuration of the inverter with a heuristic approach similar to the DTC and predicting future currents not for each possible configurations but only for the chosen one and for null voltages. Then the selected active configuration or a configuration that leads to null voltages is applied.

\section{B. Two-Configuration Predictive Control}

Another approach consists in applying successively two configurations of the power converter during a computation step, one of these configurations leads to null voltages. In the rest of this paper, we will call this technique the TwoConfiguration Predictive Control (2PC). There is a number of variations of this approach, but the principle is as follows.. First, the future values of load currents are predicted assuming that null voltages are applied during the whole next sampling period (free response of the system). Second, an active configuration of the inverter is selected. The values that the load current would reach if this configuration were applied during the whole following sampling period, are then computed. Finally, a duration for this configuration is calculated. Null voltages are applied for the rest of the sampling period.

Among the presented $2 \mathrm{PC}$ the main difference is the way the active configuration is selected. It is often chosen with a heuristic like with DTC : with a passive load in [13], with an induction machine in [15], with a doubly-fed induction machine in [16]. In [17] the future value of the load currents for all the possible power converter configuration are predicted (like with DPC), then the one that minimize the distance between the predicted current vector and the reference current vector is selected. In [18] a $2 \mathrm{PC}$ has been developed for a synchronous reluctance machine. The scheme introduced in [19] is revisited in the present paper.

\section{PWM Predictive Control}

The third class of predictive control schemes calculates the voltages required to reach the desired currents after a sampling period. A Pulse Width Modulation (PWM) is used to translate these desired voltages into switching orders. It has been presented e.g. in [20] for and induction machine, in [21] for a reluctance machine and in [22] for a PMSM. This approach, sometime called Dead Beat Control [23], is noted PWM Predictive Control (PPC) in this paper. It has been used in current control for inverters [24], as well as for PMSM [25] where the duty cycles are calculated by using classical Space Vector PWM (SVPWM). In this paper, we present an algebraic method to determine the duty cycle values for each leg of the inverter. A special care has been given to the realtime implementation, by reducing the amount of calculations needed compared to classical SVPWMs.

It should be noted that another approach has been presented in [26]. In this class of PCC the system behavior is predicted over more than one sampling period. It can improve performances at the expense of increased computation times making this technique incompatible with a standard industrial microcontroller board. This class of PCC is therefore out of the scope of this paper.

No comparative study between these predictive controls has ever been published in literature. In this paper a PMSM fed by a three-phase two-level voltage-source inverter is used as a common base in order to compare different predictive current controls. It should be noted that the methods that are described in this paper can be applied to other alternative-current machines (such as induction machines) and with various power converters (such as matrix converters).

The parameter sensitivity of each approach is studied by simulation. An experimental verification is performed on the same test bench and equivalent switching frequencies. This comparative study focuses on steady state and transient operations of the PMSM.

\section{SyStem COMPONENT MODELS}

\section{A. PMSM Model}

A PMSM consists in three windings (one per phase) on the stator and some permanent magnets mounted on the rotor surface (Surface Mounted PMSM) or buried inside the rotor (Interior PMSM). A surface mounted PMSM is classically modeled by a state-space equation (1) written in the $(d q)$ rotor reference frame [17]. In the case of the PMSM the rotor reference frame is aligned with the permanent flux, provided that the armature reaction is negligible.

$$
\begin{aligned}
{\left[\begin{array}{l}
\dot{i_{d}}(t) \\
\dot{i_{q}}(t)
\end{array}\right]=\left[\begin{array}{cc}
-\frac{R}{L} & \omega(t) \\
-\omega(t) & -\frac{R}{L}
\end{array}\right] \cdot\left[\begin{array}{c}
i_{d}(t) \\
i_{q}(t)
\end{array}\right] } \\
+\left[\begin{array}{ccc}
\frac{1}{L} & 0 & 0 \\
0 & \frac{1}{L} & -\frac{\omega(t)}{L}
\end{array}\right] \cdot\left[\begin{array}{c}
v_{d}(t) \\
v_{q}(t) \\
\phi
\end{array}\right]
\end{aligned}
$$

In this state-space model $i_{d}$ and $i_{q}$ are the $d$ and $q$ axis stator currents, $R$ and $L$ are the stator phase resistance and inductance respectively, $\omega$ is the rotor electrical speed, $v_{d}$ and $v_{q}$ are the stator voltages expressed in the $d q$ reference frame and $\phi$ is the flux established by the permanent magnets of the rotor.

$R, L$ and $\phi$ are considered as constants. If the sampling period $T$ is short enough to consider that the angular rotation during $\mathrm{T}$ is negligible, the PMSM can be modeled in discretetime by the means of a Taylor series expansion. A first order expansion leads to (2) where $\boldsymbol{F}, \boldsymbol{G}$ and $\underline{H}$ are given in (3).

$$
\begin{gathered}
{\left[\begin{array}{c}
i_{d}(k+1) \\
i_{q}(k+1)
\end{array}\right]=\boldsymbol{F}(k) \cdot\left[\begin{array}{c}
i_{d}(k) \\
i_{q}(k)
\end{array}\right]+\boldsymbol{G} \cdot\left[\begin{array}{c}
v_{d}(k) \\
v_{q}(k)
\end{array}\right]+\underline{H}(k)} \\
\boldsymbol{F}(k)=\left[\begin{array}{cc}
1-\frac{R T}{L} & T \omega(k) \\
-T \omega(k) & 1-\frac{R T}{L}
\end{array}\right] \\
\boldsymbol{G}=\left[\begin{array}{cc}
\frac{T}{L} & 0 \\
0 & \frac{T}{L}
\end{array}\right] \quad \underline{H}(k)=\left[\begin{array}{c}
0 \\
-\frac{T \omega(k)}{L} \phi
\end{array}\right]
\end{gathered}
$$

The voltage vector $\left[v_{d}(k) \quad v_{q}(k)\right]^{T}$ can be expressed from the inverter switching state vector or the duty cycles of the switching state vector. 


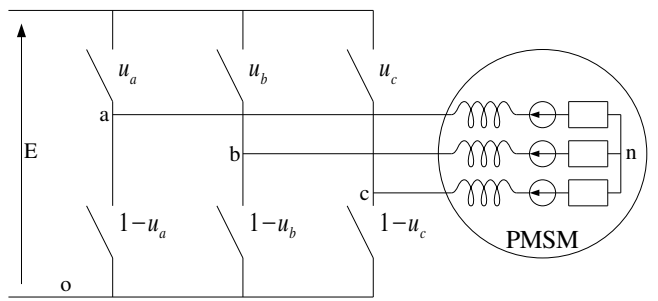

Fig. 1. Simplified Representation of the Considered System

TABLE I

SWITCHING STATE OF INVERTER LEGS AND CORRESPONDING CONFIGURATION NUMBERS $(i)$

\begin{tabular}{c||c|c|c|c|c|c|c|c}
$i$ & 0 & 1 & 2 & 3 & 4 & 5 & 6 & 7 \\
\hline \hline$u_{a}$ & 0 & 1 & 1 & 0 & 0 & 0 & 1 & 1 \\
\hline$u_{b}$ & 0 & 0 & 1 & 1 & 1 & 0 & 0 & 1 \\
\hline$u_{c}$ & 0 & 0 & 0 & 0 & 1 & 1 & 1 & 1
\end{tabular}

\section{B. Inverter model}

For a two-level, three-phase voltage inverter as presented in Fig. 1, there are two switching states per leg. So there is a total of eight possible switching states which are summarised in Tab. I.

Assuming a balanced load, it can be demonstrated that the phase-to-neutral voltages are expressed as functions of the half-bridge voltages (4).

$$
\left[\begin{array}{c}
v_{a n}(k) \\
v_{b n}(k) \\
v_{c n}(k)
\end{array}\right]=\frac{1}{3} \cdot\left[\begin{array}{ccc}
2 & -1 & -1 \\
-1 & 2 & -1 \\
-1 & -1 & 2
\end{array}\right] \cdot\left[\begin{array}{c}
v_{a o}(k) \\
v_{b o}(k) \\
v_{c o}(k)
\end{array}\right]
$$

1) Inverter model and switching states: If $u_{x}(x \in\{a, b, c\})$ is defined as an integer that represents the state of the leg $x$ (if $u_{x}=0$ then $v_{x o}=0$; if $u_{x}=1$ then $v_{x o}=E$ ) then phaseto-neutral voltages can be expressed as functions of inverter leg states (5).

$$
\left[\begin{array}{l}
v_{a n}(k) \\
v_{b n}(k) \\
v_{c n}(k)
\end{array}\right]=\frac{E}{3} \cdot\left[\begin{array}{ccc}
2 & -1 & -1 \\
-1 & 2 & -1 \\
-1 & -1 & 2
\end{array}\right] \cdot\left[\begin{array}{l}
u_{a}(k) \\
u_{b}(k) \\
u_{c}(k)
\end{array}\right]
$$

Stator voltages expressed in the $\alpha \beta$ stator reference frame are obtained using the transformation (6).

$$
\left[\begin{array}{l}
v_{\alpha}(k) \\
v_{\beta}(k)
\end{array}\right]=\sqrt{\frac{2}{3}} \cdot\left[\begin{array}{ccc}
1 & -\frac{1}{2} & -\frac{1}{2} \\
0 & \frac{\sqrt{3}}{2} & -\frac{\sqrt{3}}{2}
\end{array}\right] \cdot\left[\begin{array}{l}
v_{a n}(k) \\
v_{b n}(k) \\
v_{c n}(k)
\end{array}\right]
$$

With this transformation, thanks to the term $\sqrt{\frac{2}{3}}$, the scalar product of current and voltage vectors directly leads to the active power.

Applying (5) in (6) leads to express stator voltages in the $\alpha \beta$ reference frame as functions of inverter leg states. Finally stator voltages in the $(d q)$ rotor flux reference frame can be expressed as functions of inverter leg states using a rotation matrix (7).

$$
\begin{aligned}
{\left[\begin{array}{l}
v_{d}(k) \\
v_{q}(k)
\end{array}\right] } & =E \sqrt{\frac{2}{3}} \cdot \boldsymbol{M}(k) \cdot\left[\begin{array}{ccc}
1 & -\frac{1}{2} & -\frac{1}{2} \\
0 & \frac{\sqrt{3}}{2} & -\frac{\sqrt{3}}{2}
\end{array}\right] \cdot\left[\begin{array}{l}
u_{a}(k) \\
u_{b}(k) \\
u_{c}(k)
\end{array}\right] \\
& =\boldsymbol{M}(k) \cdot \boldsymbol{D} \cdot \underline{u}(k)
\end{aligned}
$$

In (7), $\boldsymbol{M}(k)=\left[\begin{array}{cc}\cos \theta(k) & \sin \theta(k) \\ -\sin \theta(k) & \cos \theta(k)\end{array}\right]$ where $\theta$ is the angular rotor position, $\boldsymbol{D}$ is a constant matrix and the leg state vector is $\underline{u}(k)=\left[\begin{array}{lll}u_{a}(k) & u_{b}(k) & u_{c}(k)\end{array}\right]$.

It can be noted that configurations 0 and 7 , corresponding to $u_{a}=u_{b}=u_{c}=0$ and $u_{a}=u_{b}=u_{c}=1$ respectively (Tab. I), both lead to null voltages. Indeed, they correspond to the free response of the system. Therefore, there are 8 configurations that lead to 7 distinct stator voltage vectors.

2) Inverter model and duty cycles: $\rho_{\lambda}(k)$ is the duty cycle of the leg $\lambda(\lambda \in\{a, b, c\})$ at the $k^{t h}$ switching period $T$. Furthermore, $\overline{v_{d, q}}(k)$ is defined as the mean value of $v_{d, q}(t)$ during this period. $\rho_{\lambda}$ and $\overline{v_{d, q}}(k)$ can therefore be written as:

$$
\begin{aligned}
\rho_{\lambda}(k) & =\frac{1}{T} \int_{k T}^{(k+1) T} u_{\lambda}(t) d t \\
\bar{v}_{d, q}(k) & =\frac{1}{T} \int_{k T}^{(k+1) T} v_{d, q}(t) d t
\end{aligned}
$$

where $u_{\lambda}$ is the switching function as defined before.

If $\underline{\rho}(k)=\left[\begin{array}{lll}\rho_{a}(k) & \rho_{b}(k) & \rho_{c}(k)\end{array}\right]^{T}$ is the duty cycle vector, (7) can be expressed as:

$$
\left[\begin{array}{l}
\bar{v}_{d}(k) \\
\bar{v}_{q}(k)
\end{array}\right]=\boldsymbol{M}(k) \cdot \boldsymbol{D} \cdot \underline{\rho}(k)
$$

where matrices $\boldsymbol{M}(k)$ and $\boldsymbol{D}$ is defined above.

\section{Control Schemes}

\section{A. Direct Predictive Control}

If $\underline{X}(k)=\left[\begin{array}{ll}i_{d}(k) & i_{q}(k)\end{array}\right]^{t}$ is the state vector, applying (7) in (2) yields $X_{i}(k+1)$ the state vector that would be achieved after a sampling period during which the $i^{\text {th }}$ configuration would have been used.

$$
\underline{X}_{i}(k+1)=\boldsymbol{F}(k) \cdot \underline{X}(k)+\boldsymbol{G} \cdot \boldsymbol{M}(k) \cdot \boldsymbol{D} \cdot \underline{u}_{i}(k)+\underline{H}(k)
$$

In this model, $\underline{u}_{i}(k)$ (leg state vector corresponding to the $i^{t h}$ configuration, see Tab. I for a correspondence with the switching state) is the control vector. Then 7 different state vectors can be calculated.

At each computation cycle, the stator currents and angular position are measured in order to compute the state vector $\underline{X}$ and $\boldsymbol{F}, \boldsymbol{M}$ and $\underline{H}$. For each configuration $i(i=1 \ldots 7)$, a prediction of $X_{i}(k+1)$ is calculated using (11). For a desired state $\underline{X}^{\#}$, the algorithm selects the configuration which minimizes a cost function. This cost function can be the distance between $\underline{X}_{i}(k+1)$ and $\underline{X}^{\#}$ (Fig. 2), and can expressed by (12).

$$
\left|\underline{X}_{\text {select }}(k+1)-\underline{X}^{\#}\right|=\min _{1 \leq i \leq 7}\left|\underline{X}_{i}(k+1)-\underline{X}^{\#}\right|
$$

The selected configuration is applied for the following sampling period. In order to reduce the number of switches changing state inside the inverter, when the free response minimises 


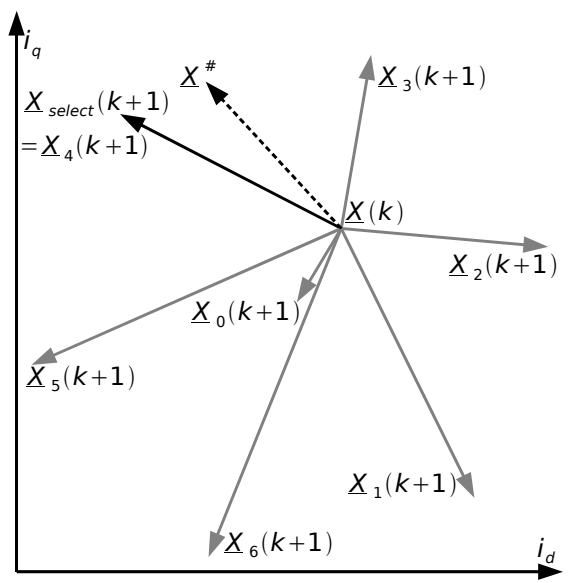

Fig. 2. State Space Representation of Direct Predictive Control

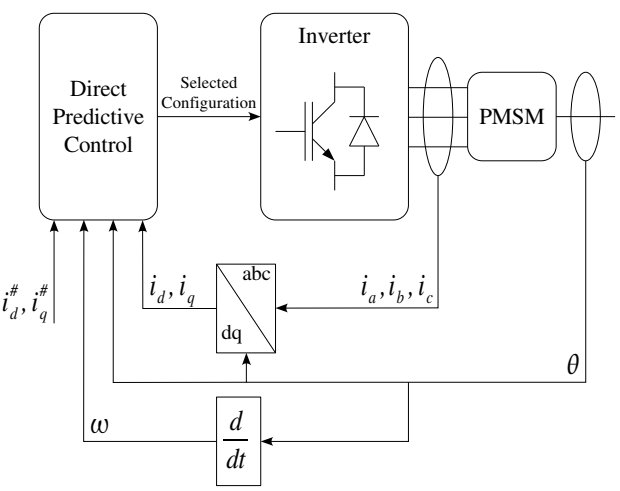

Fig. 3. Bloc Diagram of Direct Predictive Control

the cost function, configuration 0 is used if the previous configuration is number 1,3 or 5 otherwise configuration 7 is used.

The block diagram and the steps of DPC are presented in Fig. 3 and Fig. 4 respectively.

More complicated cost functions can be considered where a balance of objectives is introduced. Minimizing the distance between $\underline{X}_{\text {select }}(k+1)$ and $\underline{X}^{\#}$ is a way to guarantee the best performances in terms of accuracy and velocity. The power losses inside the system may not be minimized. The electromagnetic compatibility issues are not addressed either. It is possible to obtain a trade-off between these various objectives providing cost terms in the cost function with suitable weighting factors. As the others PCCs presented here does not offer to take into account latter trade-offs, the accuracy and velocity objectives have been retained for the comparative study.

\section{B. Two-Configuration Predictive Control}

2PC uses the same model as DPC (11) in order to predict $\underline{X}_{0}(k+1)$ the state vector if null voltages are used and computes $\underline{\varepsilon X}_{0}(k+1)=\underline{X}^{\#}-\underline{X}_{0}(k+1)$ the error between the desired state vector and $\underline{X}_{0}(k+1)$.

All possible voltage vectors are then computed in the $\alpha \beta$ stator reference frame with (5) and (6). The $\alpha \beta$ reference frame is chosen because voltage vectors are constant in this

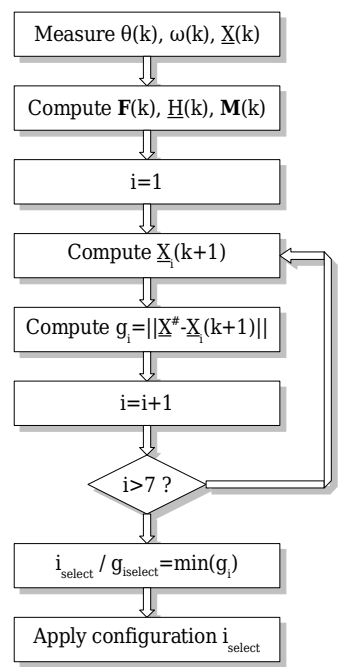

Fig. 4. Steps of Direct Predictive Control

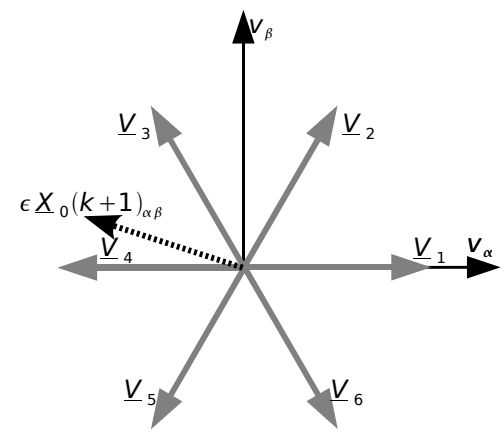

Fig. 5. Error between the desired state vector and $\underline{X}_{0}(k+1)$ and possible voltage vectors in the $\alpha \beta$ reference frame

frame, so they can be computed off-line. $\underline{\varepsilon X_{0}}(k+1)$ is expressed in the same reference frame (Fig. 5). The configuration of the inverter that minimises the angle between the corresponding voltage vector and $\varepsilon X_{0}(k+1)$ is selected. Selecting a configuration in this reference frame is quite simple: the frame can be divided in six parts so it is sufficient to check which of these sectors $\underline{\varepsilon X_{0}}(k+1)$ belongs to. For the example of Fig. 5 the chosen configuration is number 4.

Then $\underline{X}_{\text {select }}(k+1)$ is calculated using (11). This corresponds to applying the selected configuration during the whole next computing period $T$.

The selected configuration (corresponding to a forced response) is actually applied during $\gamma T(0<\gamma<1)$. Null voltages (corresponding to a free response) are applied during $(1-\gamma) T$. The resulting state vector evolution is a linear combination of $\underline{X}_{0}(k+1)$ (the free response) and $\underline{X}_{\text {select }}(k+1)$ (the selected forced response). This evolution is given by (13) and it can be shown that the state vector thus obtained is located on the segment plotted with a thin dashed line on Fig. 6 .

$$
(1-\gamma) \underline{X}_{0}(k+1)+\gamma \underline{X}_{\text {select }}(k+1)
$$

$\gamma$ can be computed in order to minimize the distance between $\underline{X}^{\#}$ and the obtained state vector. As the obtained state vector is located on the dashed line in Fig. 6, this is 


$$
\gamma=\frac{\varepsilon i_{d_{0}} \varepsilon i_{d_{0}}+\varepsilon i_{q_{0}} \varepsilon i_{q_{0}}-\varepsilon i_{d_{0}} \varepsilon i_{d_{\text {select }}}-\varepsilon i_{q_{0}} \varepsilon i_{q_{\text {select }}}}{\left(\varepsilon i_{d_{0}}-\varepsilon i_{d_{\text {select }}}\right)\left(\varepsilon i_{d_{0}}-\varepsilon i_{d_{\text {select }}}\right)+\left(\varepsilon i_{q_{0}}-\varepsilon i_{q_{\text {select }}}\right)\left(\varepsilon i_{q_{0}}-\varepsilon i_{q_{\text {select }}}\right)}
$$

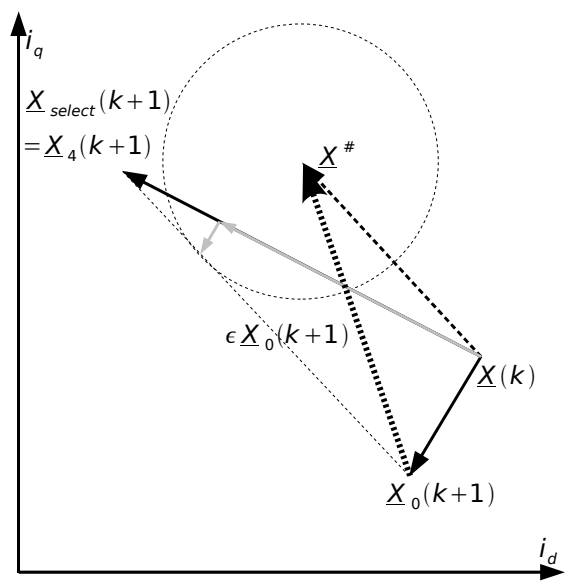

Fig. 6. State Space Representation of Two-Configurations Predictive Control

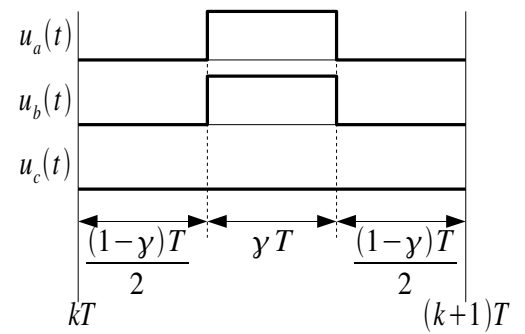

Fig. 7. Example of Switching Sequence inside a Modulation Period for the Two-Configuration Predictive Control

equivalent to finding a circle that is centered on the extremity of the reference state vector and tangent to the thin dashed segment and (14) can be used to perform this computation. A modulator is used to apply null voltages during $(1-\gamma) T$ and the selected voltages during $\gamma T$. Such a modulation sequence is pictured in Fig. 7. Then $\gamma(0<\gamma<1)$ can be seen as the duty ratio of the duration of the active configuration application compared to the modulation period.

Block diagram and algorithm steps of $2 \mathrm{PC}$ are represented in Fig. 8 and Fig. 9 respectively.

\section{PWM Predictive Control}

With PPC the stator voltages (which allow the current vector to reach the reference currents after a modulation period) are computed using the model (2). The required motor voltage are obtained from (15) under the condition that $G$ is invertible.

$$
\left[\begin{array}{l}
v_{d}(k) \\
v_{q}(k)
\end{array}\right]=\boldsymbol{G}^{-1} \cdot\left(\left[\begin{array}{c}
i_{d}^{\#} \\
i_{q}^{\#}
\end{array}\right]-\boldsymbol{F}(k) \cdot\left[\begin{array}{c}
i_{d}(k) \\
i_{q}(k)
\end{array}\right]-\underline{H}(k)\right)
$$

Generally, a classical space vector Pulse-Width Modulation (PWM) generator is used to translate these voltages into switching signals that are applied to inverter switches [2]. It is common to use trigonometrical functions to obtain these switching signals [25]. This makes implementation difficult

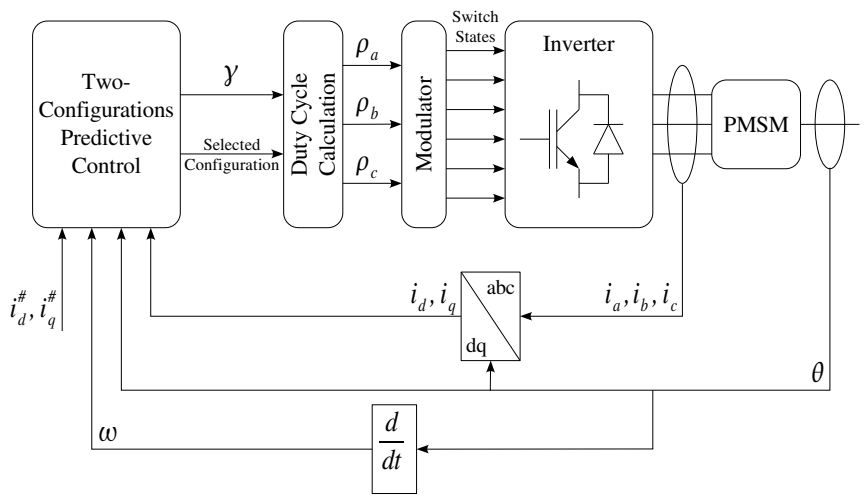

Fig. 8. Bloc Diagram of Two-configurations Predictive Control

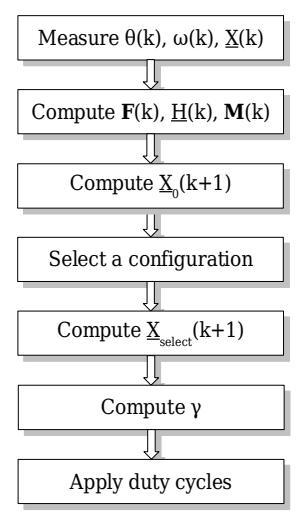

Fig. 9. Steps of Two-configurations Predictive Control

in Field-Programmable Gate Array (FPGA) or Erasable Programmable Logic Devices (EPLDs) as they mainly work with fixed-point arithmetic. Even floating-point devices such as Digital Signal Processors (DSP) can have difficulties to cope with the amount of calculations required.

Here, we detail an alternative method that uses (10) as a model of the inverter in order to determine directly duty cycles $\rho(k)$ and ease the real-time implementation.

Applying (10) in (2) leads to the model (16).

$\underline{X}(k+1)=\boldsymbol{F}(k) \cdot \underline{X}(k)+\boldsymbol{G} \cdot \boldsymbol{M}(k) \cdot \boldsymbol{D} \cdot \underline{\rho}(k)+\boldsymbol{H}(k)$

Since $M$ and $G$ are invertible, (17) can be used in order to compute the duty cycle vector that allows to reach desired currents after a modulation period.

$\boldsymbol{D} \cdot \underline{\rho}(k)=\boldsymbol{M}^{-1}(k) \cdot \boldsymbol{G}^{-1} \cdot\left(\underline{X}^{\#}-\boldsymbol{F}(k) \cdot \underline{X}(k)-\underline{H}(k)\right)$ 


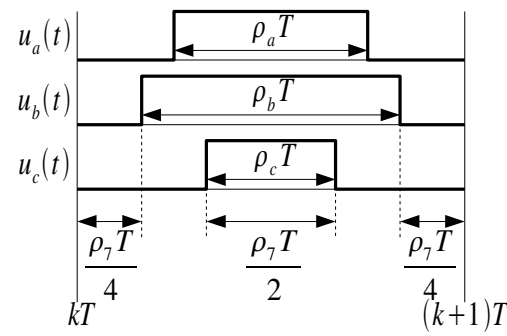

Fig. 10. Example of Switching Sequence inside a Modulation Period for the PWM Predictive Control

Eq. (18) is deduced from (17) replacing $D$ by its expression.

$$
\begin{aligned}
& {\left[\begin{array}{ccc}
1 & -\frac{1}{2} & -\frac{1}{2} \\
0 & \frac{\sqrt{3}}{2} & -\frac{\sqrt{3}}{2}
\end{array}\right] \cdot\left[\begin{array}{l}
\rho_{a}(k) \\
\rho_{b}(k) \\
\rho_{c}(k)
\end{array}\right]} \\
& =\frac{1}{E} \cdot \sqrt{\frac{3}{2}} \cdot \boldsymbol{M}^{-1}(k) \cdot \boldsymbol{G}^{-1} \cdot\left(\underline{X}^{\#}-\boldsymbol{F}(k) \cdot \underline{X}(k)-\underline{H}(k)\right) \\
& =\left[\begin{array}{l}
\rho_{1}(k) \\
\rho_{2}(k)
\end{array}\right]
\end{aligned}
$$

Eq. (18) gives one degree of freedom. Indeed, there is an infinity of duty cycle vectors that allow to reach the desired state vector after a modulation period. These duty cycle vectors lead to the same mean value of stator voltages during a modulation period. The aforementioned degree of freedom is used to adapt duty cycles to a desired modulation pattern.

Many types of modulation patterns are reported [27]-[31]. If a conventional sequence as Fig. 10 is used, then configurations $0\left(u_{a}=u_{b}=u_{c}=0\right)$ and $7\left(u_{a}=u_{b}=u_{c}=1\right)$ corresponding to null voltages are applied for a same duration.

In the case of Fig. 10 this is obtained by choosing $\rho_{c}=$ $\frac{\rho_{7}}{2}=\min \left(\rho_{a}, \rho_{b}, \rho_{c}\right)$ and $\rho_{b}=1-\frac{\rho_{7}}{2}=\max \left(\rho_{a}, \rho_{b}, \rho_{c}\right)$, where $\rho_{7}$ is the duty cycle for the null voltage application. Furthermore, it can be seen that $\rho_{b}>\rho_{a}>\rho_{c}$ and it can be noted that $\rho_{b}+\rho_{c}=1$ and $\rho_{b}-\rho_{c}=1-\rho_{7}$. These remarks are only true for the particular case of Fig. 10 a generalisation is given below.

A study of all possible cases can be summarized as follows.

$$
\begin{aligned}
& \rho_{b}+\rho_{c}=1 \Leftrightarrow\left\{\text { or } \begin{array}{l}
\rho_{b}>\rho_{a}>\rho_{c} \\
\rho_{c}>\rho_{a}>\rho_{b}
\end{array}\right. \\
& \rho_{a}+\rho_{c}=1 \Leftrightarrow\left\{\begin{array}{l}
\text { or } \begin{array}{l}
\rho_{a}>\rho_{b}>\rho_{c} \\
\rho_{c}>\rho_{b}>\rho_{a}
\end{array}
\end{array}\right. \\
& \rho_{a}+\rho_{b}=1 \Leftrightarrow\left\{\begin{array}{l}
\rho_{b}>\rho_{c}>\rho_{a} \\
\rho_{a}>\rho_{c}>\rho_{b}
\end{array}\right.
\end{aligned}
$$

and

$$
\begin{gathered}
\min \left(\rho_{a}, \rho_{b}, \rho_{c}\right)=\frac{\rho_{7}}{2} \\
\max \left(\rho_{a}, \rho_{b}, \rho_{c}\right)=1-\frac{\rho_{7}}{2}
\end{gathered}
$$

This yields to (22) and (23). These equations characterize the chosen modulation pattern.

$$
\max \left(\rho_{a}, \rho_{b}, \rho_{c}\right)+\min \left(\rho_{a}, \rho_{b}, \rho_{c}\right)=1
$$

$$
\max \left(\rho_{a}, \rho_{b}, \rho_{c}\right)-\min \left(\rho_{a}, \rho_{b}, \rho_{c}\right)=1-\rho_{7}
$$

One of (22) or (23) can be added to (18) to determine duty cycles $\rho(k)$. Eq. (22) is used in this paper.

For the example given in Fig. 10, adding the equation obtained by (22), i.e. $\rho_{b}+\rho_{c}=1$ to the two equations given by (18) gives the system (24) that can be written in a matrix form (25).

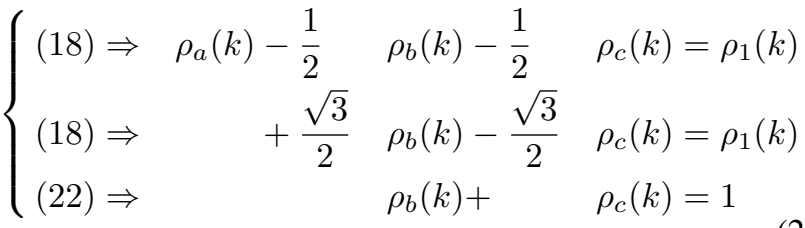

$$
\begin{aligned}
& \underbrace{\left[\begin{array}{ccc}
1 & -\frac{1}{2} & -\frac{1}{2} \\
0 & \frac{\sqrt{3}}{2} & -\frac{\sqrt{3}}{2} \\
0 & 1 & 1
\end{array}\right]}_{\boldsymbol{M}_{\boldsymbol{a}}} \cdot\left[\begin{array}{c}
\rho_{a}(k) \\
\rho_{b}(k) \\
\rho_{c}(k)
\end{array}\right]=\left[\begin{array}{c}
\rho_{1}(k) \\
\rho_{2}(k) \\
1
\end{array}\right]
\end{aligned}
$$

The matrix $\boldsymbol{M}_{\boldsymbol{a}}$ is invertible. Therefore, when $\rho_{1}$ and $\rho_{2}$ are computed, it offers a way to compute the duty cycle vector.

For the three possibilities offered by (22) $\left(\rho_{a}+\rho_{b}=1\right.$, $\rho_{b}+\rho_{c}=1$ or $\left.\rho_{a}+\rho_{c}=1\right)$, the resulting matrix is constant and invertible. Its inverse can be calculated off-line as (26), (27) and (28).

$$
\begin{aligned}
& {\left[\begin{array}{ccc}
1 & -\frac{1}{2} & -\frac{1}{2} \\
0 & \frac{\sqrt{3}}{2} & -\frac{\sqrt{3}}{2} \\
0 & 1 & 1
\end{array}\right]^{-1}=\left[\begin{array}{ccc}
1 & 0 & \frac{1}{2} \\
0 & \frac{\sqrt{3}}{3} & \frac{1}{2} \\
0 & -\frac{\sqrt{3}}{3} & \frac{1}{2}
\end{array}\right]} \\
& {\left[\begin{array}{ccc}
1 & -\frac{1}{2} & -\frac{1}{2} \\
0 & \frac{\sqrt{3}}{2} & -\frac{\sqrt{3}}{2} \\
1 & 0 & 1
\end{array}\right]^{-1}=\left[\begin{array}{ccc}
\frac{1}{2} & \frac{\sqrt{3}}{6} & \frac{1}{2} \\
-\frac{1}{2} & \frac{\sqrt{3}}{2} & \frac{1}{2} \\
-\frac{1}{2} & -\frac{\sqrt{3}}{6} & \frac{1}{2}
\end{array}\right]} \\
& {\left[\begin{array}{cccc}
1 & -\frac{1}{2} & -\frac{1}{2} \\
0 & \frac{\sqrt{3}}{2} & -\frac{\sqrt{3}}{2} \\
1 & 1 & 0
\end{array}\right]^{-1}=\left[\begin{array}{ccc}
\frac{1}{2} & -\frac{\sqrt{3}}{6} & \frac{1}{2} \\
-\frac{1}{2} & \frac{\sqrt{3}}{6} & \frac{1}{2} \\
-\frac{1}{2} & -\frac{\sqrt{3}}{2} & \frac{1}{2}
\end{array}\right]}
\end{aligned}
$$

From this, a first method can be proposed to algebraically determine duty cycles. When $\rho_{1}$ and $\rho_{2}$ are calculated, three duty cycle vectors can be obtained from (26), (27) and (28). Among these vectors one and only one is consistent with the hypothesis (19) [12]. For example, if a duty cycle vector is computed with (26), it assumes that $\rho_{b}+\rho_{c}=1$, it must verify (19) i.e. $\rho_{b}>\rho_{a}>\rho_{c}$ or $\rho_{c}>\rho_{a}>\rho_{b}$. This duty cycle vector can then be selected for application during the following modulation period.

A second method (used for real-time implementation) is proposed in order to reduce the amount of calculations. It can be shown that adding the same quantity to all duty cycles leads to the same mean stator voltages (it just changes the balance between durations of application of configurations 0 and 7). A first set of duty cycles can be obtained using (26), (27) or (28). Then the same quantity is added to $\rho_{a}, \rho_{b}$ and $\rho_{c}$ in order to obtain the desired modulation pattern property (for example, 


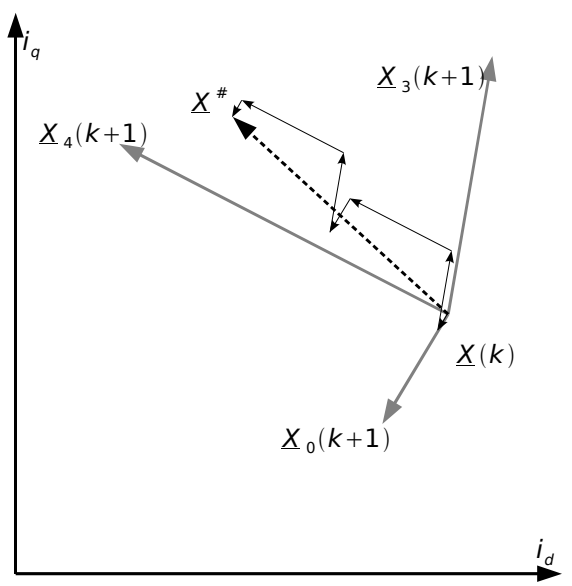

Fig. 11. State Space Representation of PWM Predictive Control

expressed by (20)). This leads to (29).

$$
\begin{aligned}
\rho_{7} & =1-\max \left(\rho_{a}, \rho_{b}, \rho_{c}\right)+\min \left(\rho_{a}, \rho_{b}, \rho_{c}\right) \\
\rho_{a}^{\prime} & =\rho_{a}-\min \left(\rho_{a}, \rho_{b}, \rho_{c}\right)+\frac{\rho_{7}}{2} \\
\rho_{b}^{\prime} & =\rho_{b}-\min \left(\rho_{a}, \rho_{b}, \rho_{c}\right)+\frac{\rho_{7}}{2} \\
\rho_{c}^{\prime} & =\rho_{c}-\min \left(\rho_{a}, \rho_{b}, \rho_{c}\right)+\frac{\rho_{7}}{2}
\end{aligned}
$$

Finally this new duty cycle vector $\left(\left[\begin{array}{lll}\rho_{a}^{\prime} & \rho_{b}^{\prime} & \rho_{c}^{\prime}\end{array}\right]^{t}\right)$ is applied during the next modulation period.

These methods of duty cycle calculation are independent of the voltage space vector sector. They use trigonometrical functions for the calculation of the terms of $M$ (in (17)). But these terms are already computed in order to obtain currents or voltages in the rotor flux reference frame (e.g. in (7)). So the values of the duty cycle of each inverter legs are obtained with no additional trigonometrical computations. This makes it efficient for real time implementation. As they use modulation pattern similar to the one used with conventional SVPWM, they lead to the same performances in terms of Total Harmonic Distortions (THD), maximum voltage...

Using a PWM, PPC applies two different active configurations and null voltage configurations. The configuration succession leads to a state vector evolution that can be represented in Fig. 11. The overall principle of PPC is illustrated in Fig. 12 and Fig. 13.

\section{Conditions of the Comparative Study}

The comparative study is conducted using a 1.6kW PMSM. Its characteristics are given in Tab. II. The inverter DC bus voltage is $540 \mathrm{~V}$ and the dead-time of inverter switches is set to $3 \mu \mathrm{s}$.

\section{A. References}

In the case of a PMSM, the electromagnetic torque is proportional to the current $i_{q}$ and the minimization of the Joule power losses leads to fix the current $i_{d}$ to zero. Consequently, reference values are $i_{d}^{\#}=0$ and $i_{q}^{\#}$ proportional to the desired torque $T_{e}^{\#}\left(i_{q}^{\#}=\frac{T_{e}^{\#}}{p * \phi}\right)$. Meaningful transient operations are obtained by changing the sign of the desired torque value.

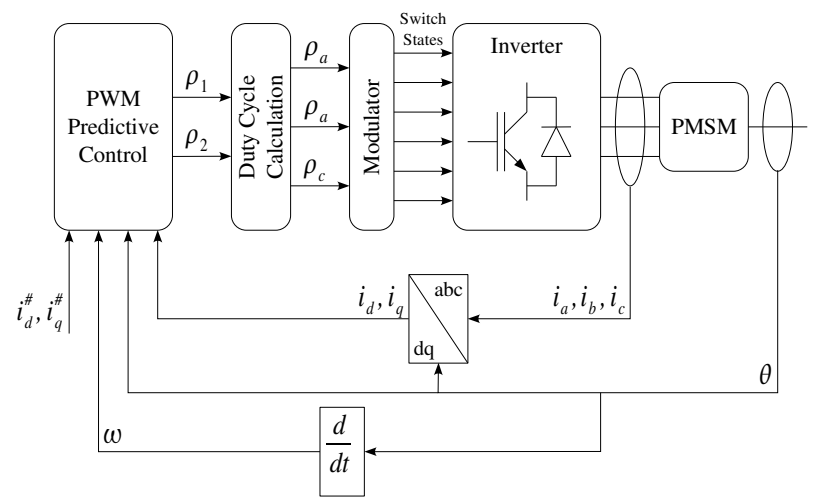

Fig. 12. PWM Predictive Control Principle

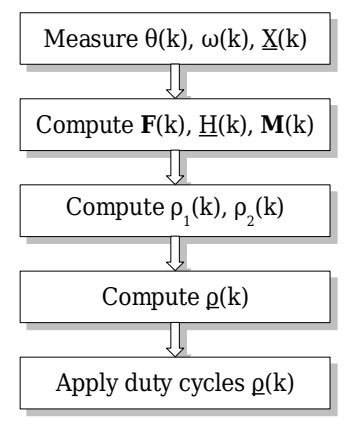

Fig. 13. Flowchart of PWM Predictive Control

The comparative study is performed for the three control schemes with references corresponding to the rated torque $\left(i_{q}^{\#}=5.75 \mathrm{~A}\right.$ and $\left.i_{d}^{\#}=0 \mathrm{~A}\right)$. It is worth noting that the control schemes tested here are equivalent to torque control. Indeed, there is no speed loop. Generally, torque controllers are used inside a speed loop. In our case, Angular speed (here $\approx 2000 \mathrm{rpm}$ ) is not controlled, it is just an outcome of mechanical parameters of the test bench like inertia, frictions or load torque. PCC performances are not affected if they are used inside a speed loop.

\section{B. Sampling Frequencies}

DPC computations are scheduled by a timer interrupt with a fixed period as small as possible (i.e. just larger than the computation duration). With the computing unit used for experimental study, the smallest period that can be achieved is $26 \mu \mathrm{s}$. The same value is then also chosen for the simulation study.

TABLE II

PARAMETERS OF THE PMSM

\begin{tabular}{c|rl} 
Rated Torque & 5 & $\mathrm{Nm}$ \\
\hline Rated Speed & 3000 & $\mathrm{rpm}$ \\
\hline Rated Voltage & 540 & $\mathrm{~V}$ \\
\hline$R$ & 2.06 & $\Omega$ \\
\hline$L$ & 9.15 & $\mathrm{mH}$ \\
\hline$\phi$ & 290 & $\mathrm{mWb}$ \\
\hline Number of pole pairs (p) & 3 &
\end{tabular}


With DPC, between two computation cycles, the number of leg state changes can be zero (if $i_{\text {select }}(k)=i_{\text {select }}(k+1)$ ), one (e.g. $i_{\text {select }}(k)=7$ and $i_{\text {select }}(k+1)=2$ ), two (e.g. $i_{\text {select }}(k)=2$ and $\left.i_{\text {select }}(k+1)=4\right)$ or even three (e.g. $i_{\text {select }}(k)=1$ and $\left.i_{\text {select }}(k+1)=4\right)$. Therefore, DPC leads to an unpredictable, variable switching frequency. Experimental results show that the mean switching frequency depends on the operating point, e.g. the mean number of leg state changes between two computing periods is 0.84 at $200 \mathrm{rpm} / 0.9 \mathrm{Nm}$, 1.06 at $200 \mathrm{rpm} / 5 \mathrm{Nm}$ or 1.25 at $2000 \mathrm{rpm} / 5 \mathrm{Nm}$.

With $2 \mathrm{PC}$, there are 4 commutations per sampling period if the selected configuration number is 2, 4 or 6 (see Fig. 7 for an example). For the other configuration numbers, there are 2 leg state changes per sampling period. Therefore, on average, there are 3 leg state changes per sampling period. In order to have a similar switching frequency at 2000rpm and the rated torque, the modulation period of $2 \mathrm{PC}$ is fixed to $62 \mu \mathrm{s}$ $(\approx 3 * 26 \mu \mathrm{s} / 1.25)$ for the simulation and the experimental study.

With PPC, there are 6 leg state changes per sampling period (Fig. 10). The modulation period is therefore fixed to $125 \mu \mathrm{s}$ $(\approx 6 * 26 \mu \mathrm{s} / 1.25)$.

\section{Sensitivity of the Model Parameters}

In this section and in the following one, simulation and experimental conditions are detailed, results are pictured and compared. Discussion is given in section VII.

In order to evaluate the sensitivity to changes in the model parameters of the three algorithms, a simulation study is performed under a Matlab/Simulink environment.

The PMSM is modeled as (1) with the values given in Tab. II. In so-called "Test 0 ", the inverter is supposed to be ideal. For "Test 1" and so on, the dead-time is set to $3 \mu \mathrm{s}$, conducting diodes are modelled with $1.1 \mathrm{~V}$ threshold voltage drop in series with $0.03 \Omega$ resistor and IGBTs are modelled with $2.7 \mathrm{~V}$ threshold voltage drop in series with $0.01 \Omega$ resistor.

The comparative study is performed by changing the parameters of the PMSM while parameters used for control calculations remain unchanged. As an example with "Test 2", the PMSM phase resistor is supposed to be two times the rated value for the simulated PMSM although the tested predictive controls use the rated value for calculations. This corresponds to an increase in temperature. For "Test 3" and "Test 4" the flux for the simulated PMSM is set respectively to 1.1 times and 0.8 times the rated value. The former corresponds to a brand new machine, and the latter to a heavily used machine. Inductance evolution is not considered because it does not vary with temperature or aging. These parameter variations are taken from [32] and summarised in Tab. III.

Stator currents in the dq-reference plane are pictured in Fig. 14 for "Test 1". Amplitudes of ripples for both controlled currents $\left(\Delta i_{d}\right.$ and $\left.\Delta i_{q}\right)$ and static errors $\left(\varepsilon i_{d}\right.$ and $\varepsilon i_{q}$ ) are reported in Fig. 15 for each test and each control scheme.

In all test cases, current ripple (for example with $\Delta i_{d}+\Delta i_{q}$ ) is larger with DPC and smaller with PPC. Furthermore, the sums of current ripple amplitudes are quite insensitive to inverter imperfections and parameter uncertainties (resistor and flux values).
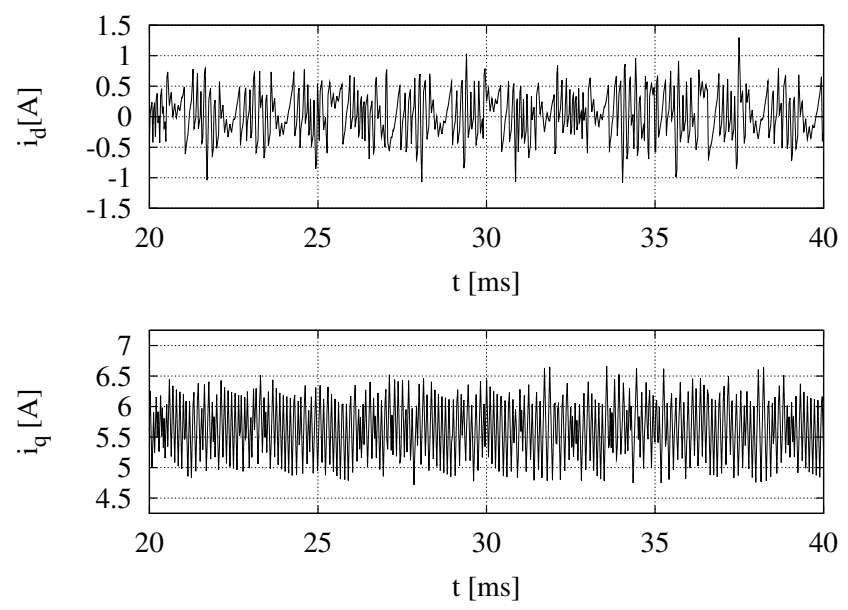

(a) DPC
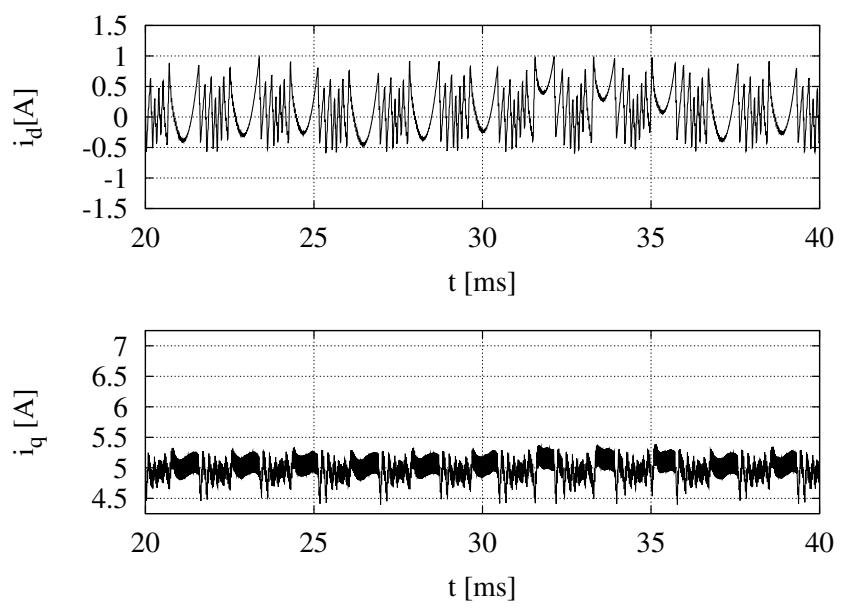

(b) $2 \mathrm{PC}$
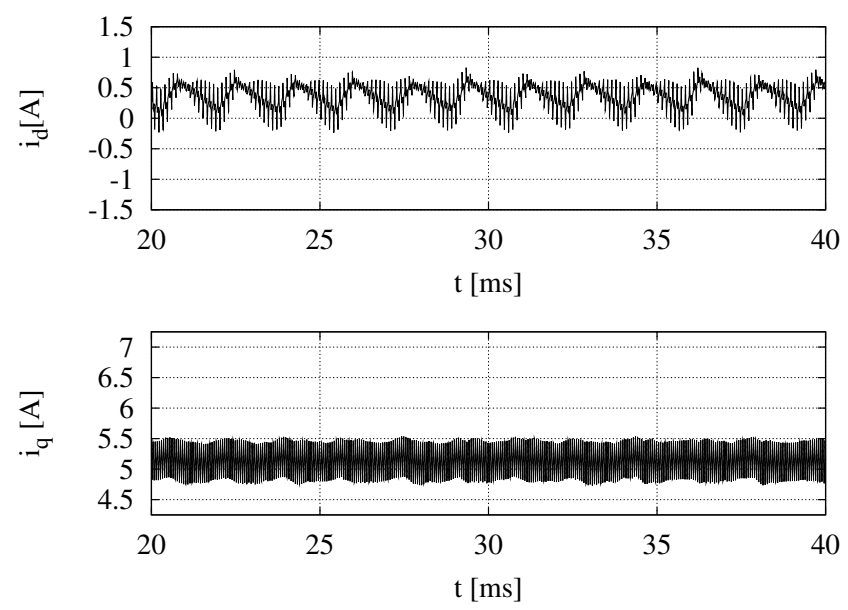

(c) PPC

Fig. 14. Stator currents in the dq-reference plane for "Test 1". 
TABLE IV

Results of the Study of the Sensitivity to Model Parameter

TABLE III

Conditions of the Study of the Sensitivity to Model Parameter

\begin{tabular}{c|c|c|c} 
Test & Inverter & $R$ & $\phi$ \\
\hline 0 & ideal & rated value & rated value \\
\hline 1 & non ideal & rated value & rated value \\
\hline 2 & non ideal & 2 times the rated value & rated value \\
\hline 3 & non ideal & rated value & 1.1 times the rated value \\
\hline 4 & non ideal & rated value & 0.8 times the rated value
\end{tabular}

Test 0

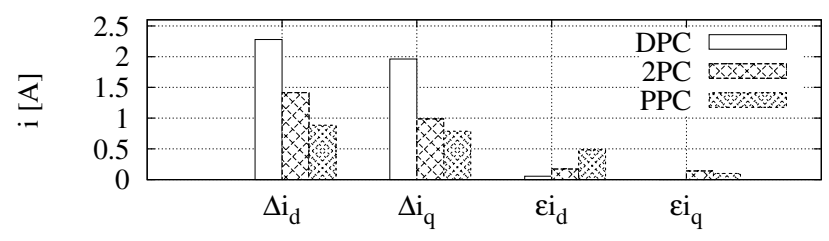

Test 1

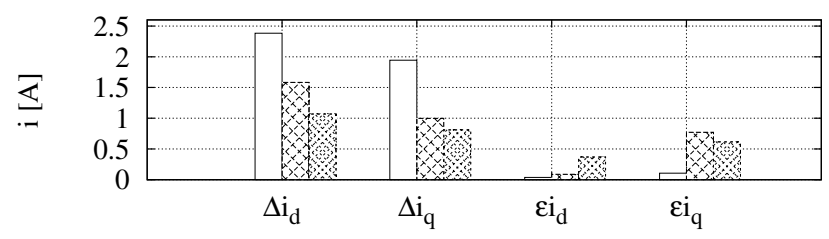

Test 2

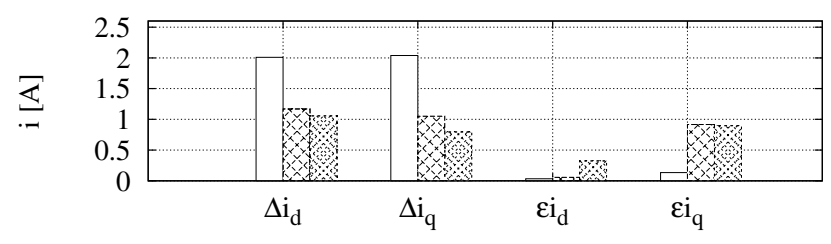

Test 3

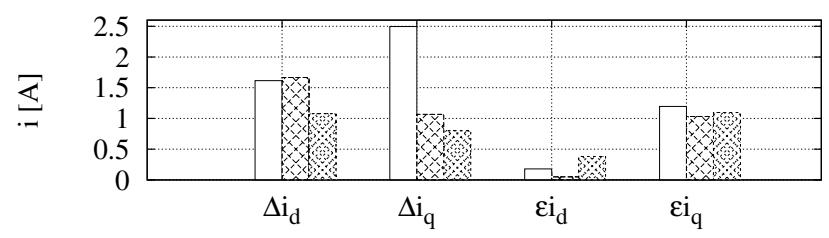

Test 4

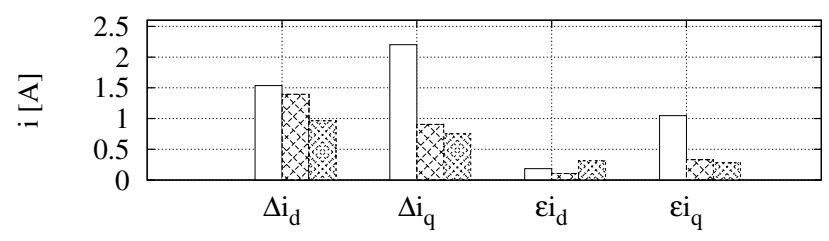

Fig. 15. Amplitudes of Oscillations and Static Errors for the Different Tests

\begin{tabular}{ll|c|c|c} 
& & DPC & 2PC & PPC \\
\hline$\Delta i_{d}+\Delta i_{q}$ & all tests & bad & medium & good \\
\hline$\varepsilon i_{d}+\varepsilon i_{q}$ & tests $0-2$ & good & medium & bad \\
\hline$\varepsilon i_{d}+\varepsilon i_{q}$ & test 3 & medium & medium & medium \\
\hline$\varepsilon i_{d}+\varepsilon i_{q}$ & test 4 & bad & good & good
\end{tabular}

Without parameter uncertainties ("Test 0 " and "Test 1") static errors are smaller with DPC and larger with PPC. This is not the case when the rotor flux is not well known ("Test 3" and "Test 4") : in these cases 2PC and PPC show similar static error sums while this sum is larger for DPC. PPC and 2PC static errors are more sensitive to inverter imperfections whereas PPC static errors are more sensitive to flux uncertainty.

The above comments, based on Fig. 15, are summarised in Tab. IV.

\section{EXPERIMENTAL COMPARISON}

The experimental study is conducted with two identical 1.6kW PMSM and a 4096-pulse incremental encoder. The first PMSM is used as a motor, the second one is used as a load torque generator : it feeds a resistor through a diode rectifier. The motor is driven by a commercial $15 \mathrm{~kW}$ threephase inverter based on Insulated-Gate Bipolar Transistors (IGBTs), supplied through two voltage sources (XANTREX XKW 300-10) connected in series, which provide 540V with a current limitation of about 10A. Three LEM current sensors (LEM LA 100P) are used.

All control schemes are implemented in C language and computations are performed on a DSpace DS1104 controller board. Data recording and reference value settings are performed within the ControlDesk environment. Phase currents and spectra are recorded with some Tektronix hardware: an A 6302 current sensor, an AM 503 current probe amplifier and a TPO 4032 digital oscilloscope. The 250kHz-bandwidth spectrum is obtained applying a Hamming window.

In order to take into account the delay (caused by the duration of the calculations) between the current sensing and the application of the voltage to the motor, the compensation method proposed in [25] is used for all control schemes.

\section{A. Experimental results}

For the sake of space, results are shown for one operating point only: rated torque and almost 2000rpm (the load torque is produced by the second PMSM). This is the point we used in the previous section to select the sampling frequencies of the three algorithms to get the same switching frequency. Experimental results are not presented for the rated speed because to obtain the rated speed and the rated torque simultaneously the load resistor value that should be used is not available in the laboratory. A companion paper (available on-line) provides the experimental results performed for the present study for other operating points [33]. 


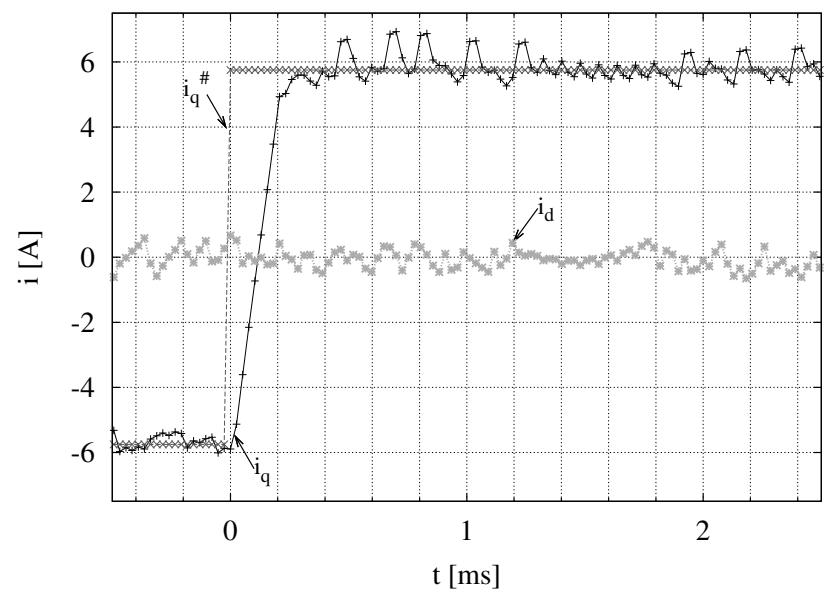

(a) DPC

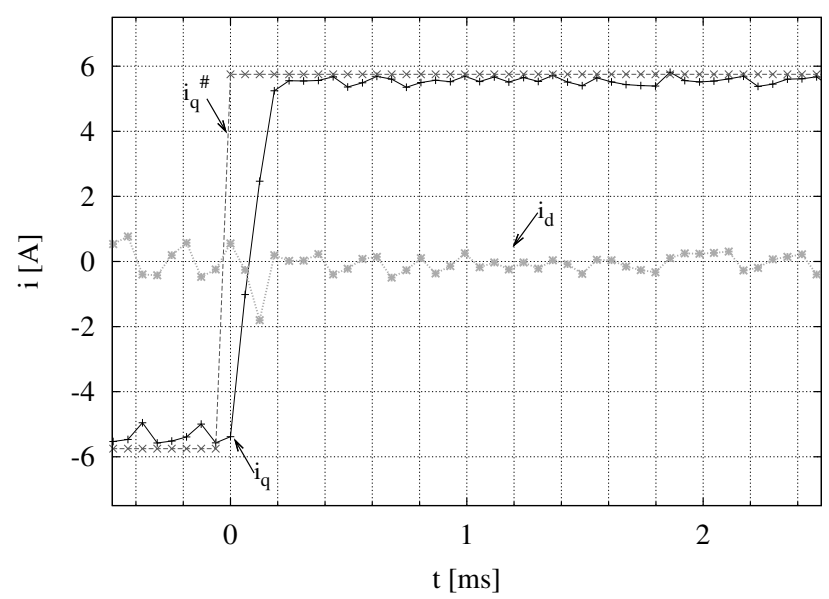

(b) $2 \mathrm{PC}$

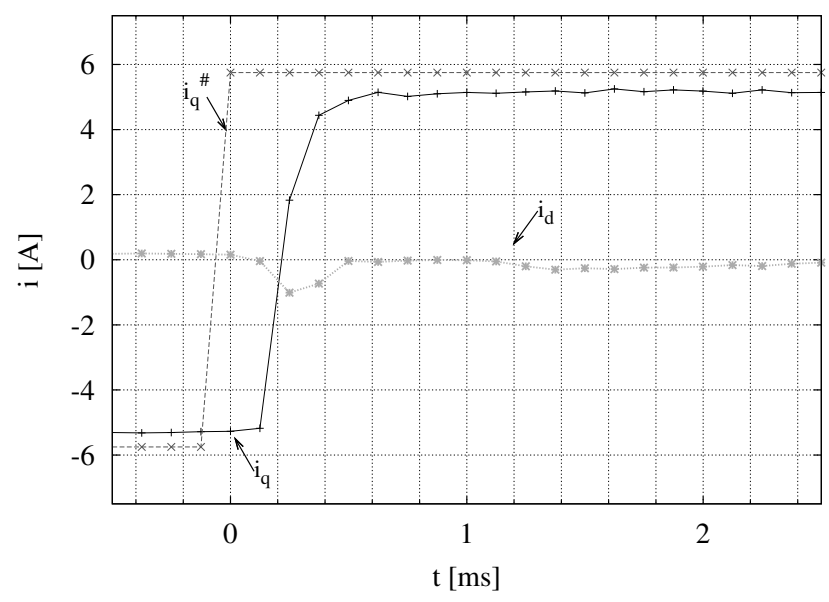

(c) PPC

Fig. 16. Phase Currents in the Rotor Frame during Transient Operation (short time scale) d- and q-axis currents are shown in Fig. 16 and Fig. 17. For the three control schemes, the torque inversion (Fig. 16) is very fast (almost $200 \mu \mathrm{s}$ ) and without overshoot. It can be seen that the transient variation of the current on the q-axis has no important consequence on the current control on the d-axis.

During this experiment, the rotor speed is not controlled, in about $70 \mathrm{~ms}$ it grows from almost -2000rpm to almost 2000rpm. It is worth noting that this evolution of angular speed does not have a significant influence on static errors (Fig. 17): during steady state operation (after a few tenth of milliseconds), the angular velocity is quite constant and static errors on stator currents in the dq-frame are not very different from the ones obtained just after the torque inversion. Static errors are similar to the simulation "Test 1": almost zero for DPC, larger for 2PC and even larger for PPC. Therefore, it can be concluded that they are not due to the change in angular velocity, but to the fact that the inverter is considered as ideal in the model.

Similar results are obtained for others operating points.

After transient, current ripple amplitude seems important for DPC (Fig. 17(a)) and almost negligible for PPC (Fig. 17(c)) but it should be noted that these current are sampled in the ControlDesk environment i.e. with the same sampling frequency as the algorithm (26 $\mu$ s for DPC, $62 \mu$ s for $2 \mathrm{PC}$ and $125 \mu$ s for PPC). Therefore, Fig. 16 can not be used to draw any conclusion about current ripple amplitudes.

A phase current measured with an oscilloscope is shown in Fig. 18. The sampling frequency $(100 \mathrm{kHz})$ is the same for the three algorithms. It can be seen that, whatever the control scheme and in spite of very different computing periods, the phase current amplitude is almost the same, it is just a little bit reduced for PPC. Total Harmonic Distortions (THD) are fairly similar : $10.8 \%$ for DPC, $15.2 \%$ or $2 \mathrm{PC}$ and $12.8 \%$ for PPC.

With DPC, ripples are independent of the operating point but the switching frequency varies. This observation is consistent with the analysis found in [34]. With 2PC and PPC, switching frequencies are constant but ripples are a little larger for high torque and the larger the speed, the larger the amplitude of ripples.

Phase current spectra, for the operating point considered in Fig. 18 are shown in Fig. 19. Very different harmonic distributions can be seen. With PPC (Fig. 19(c)), harmonics are very well concentrated near the sampling frequency $(8 \mathrm{kHz})$ and its multiples. The harmonic distributions of 2PC (Fig. 19(b)) and DPC (Fig. 19(a)) are distributed over a large frequency span. For 2PC, it spreads between 0 and $10 \mathrm{kHz}$. For DPC, the harmonic content is spread evenly between 0 and $20 \mathrm{kHz}$ but with a smaller amplitude.

\section{DISCUSSION}

With DPC, during a sampling period, there are only 7 possible directions for the state vector so the reference point cannot be exactly reached. A limit cycle can appear when the state vector is close to the reference point and the smallest the sampling period, the lowest the ripple amplitude. With 


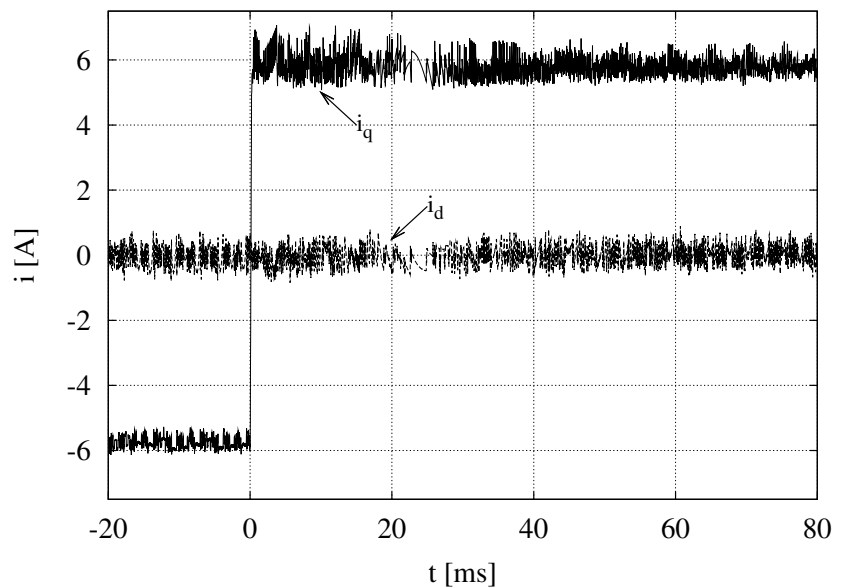

(a) DPC

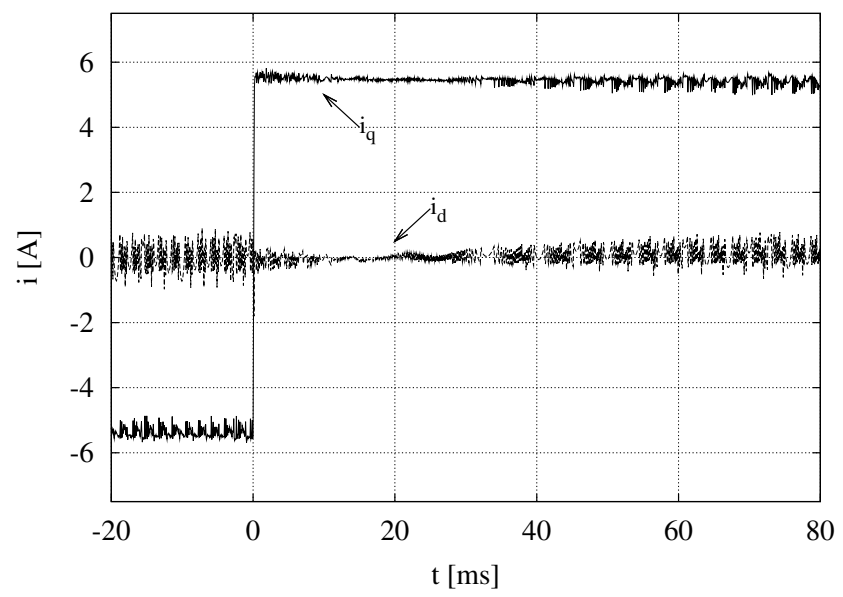

(b) $2 \mathrm{PC}$

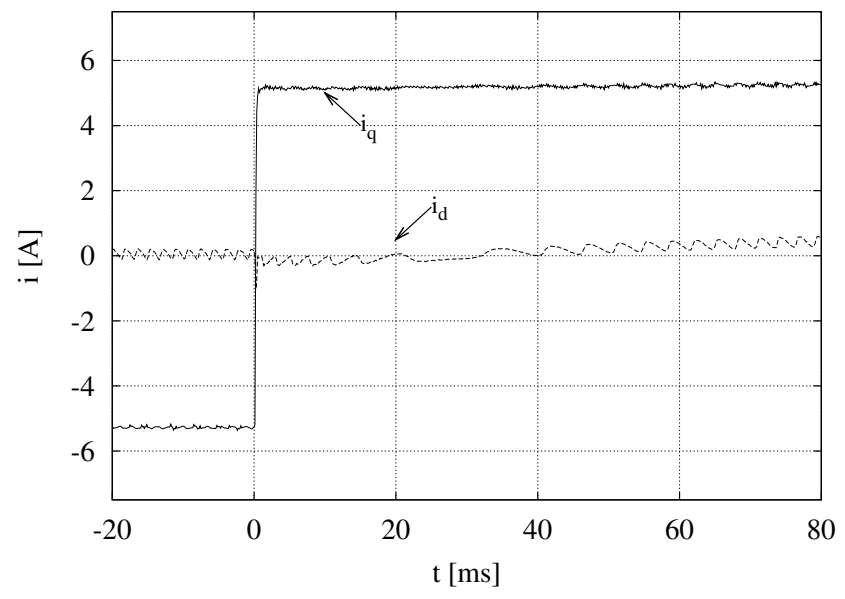

(c) PPC

Fig. 17. Phase Currents in the Rotor Frame during Transient Operation (long time scale)

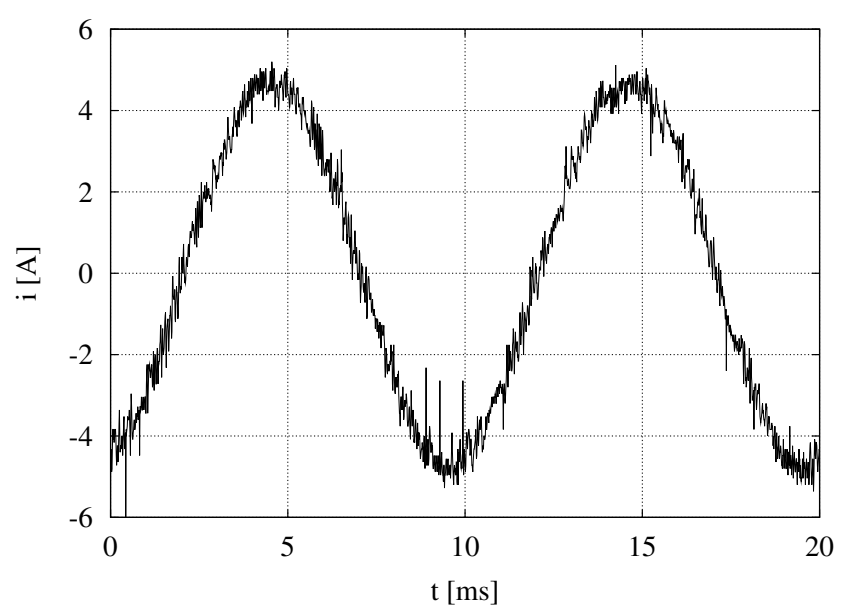

(a) DPC

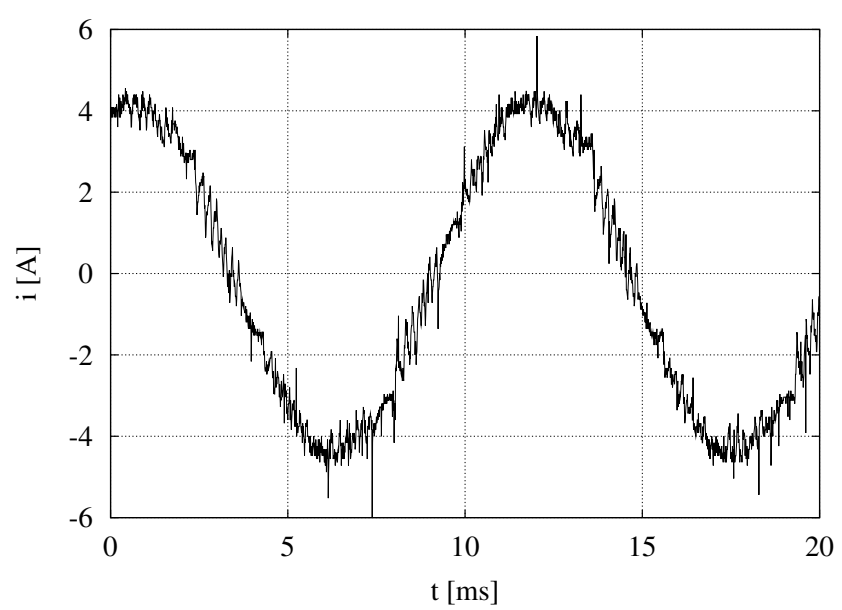

(b) $2 \mathrm{PC}$

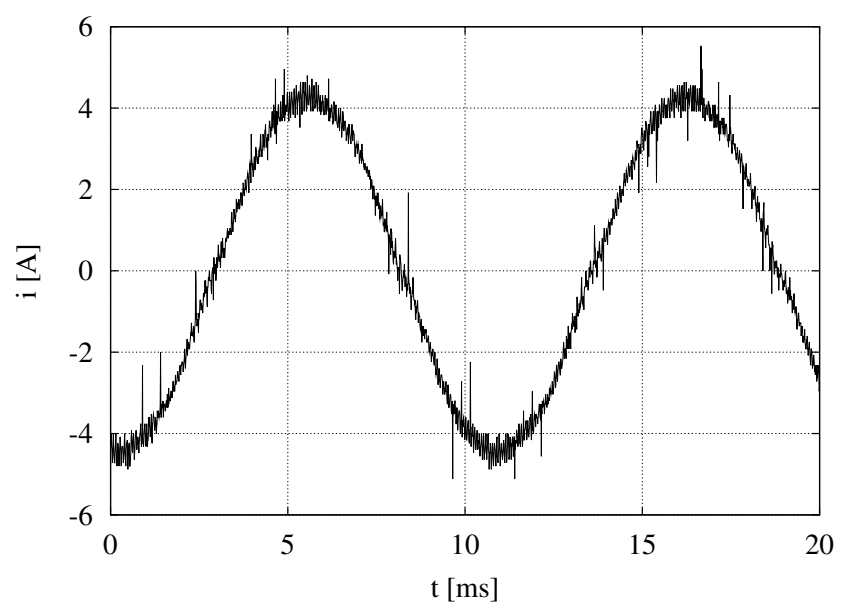

(c) PPC

Fig. 18. Phase Current during Steady State Operation 
TABLE V

Computing Durations for the Tested Control Schemes When IMPLEMENTED ON THE SAME COMPUTATIONAL UNIT

\begin{tabular}{c|c|c}
$\mathrm{DPC}$ & $2 \mathrm{PC}$ & $\mathrm{PPC}$ \\
\hline $13.5 \mu \mathrm{s}$ & $15.5 \mu \mathrm{s}$ & $16.5 \mu \mathrm{s}$
\end{tabular}

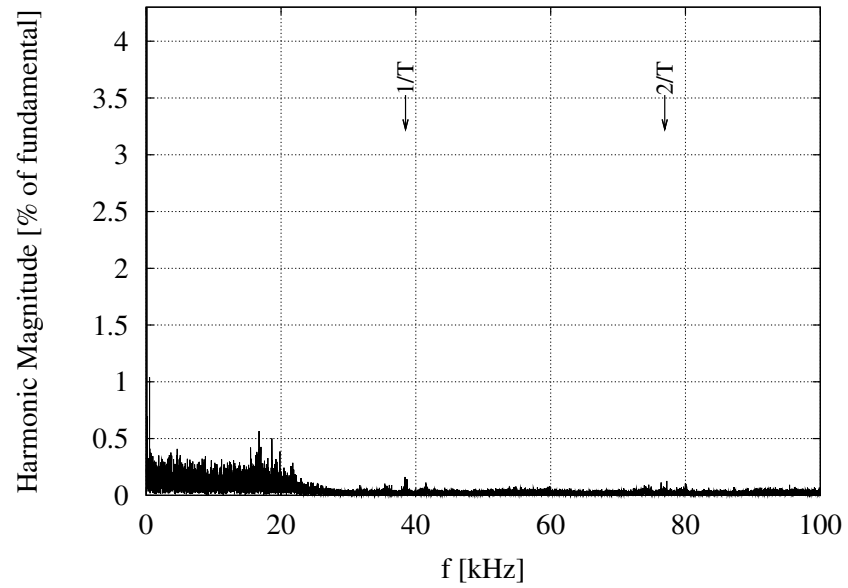

(a) DPC

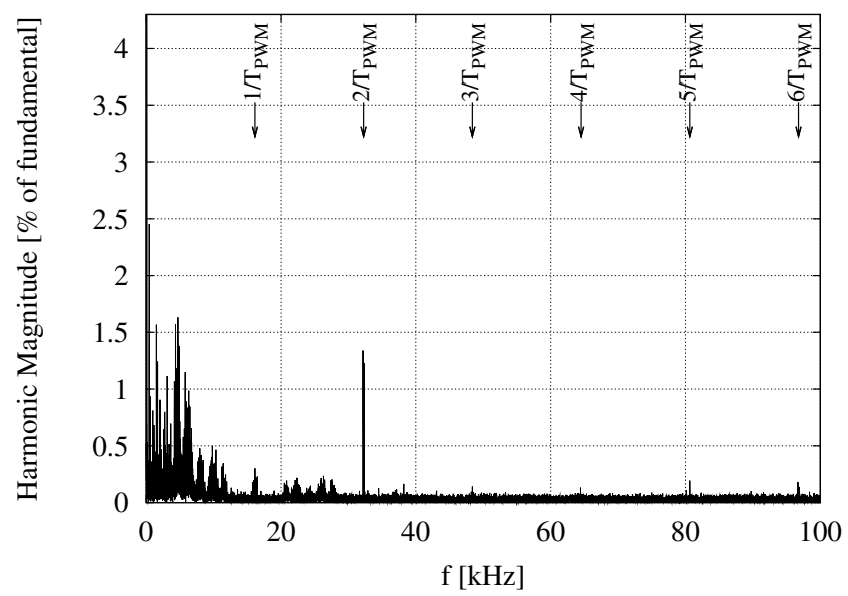

(b) $2 \mathrm{PC}$

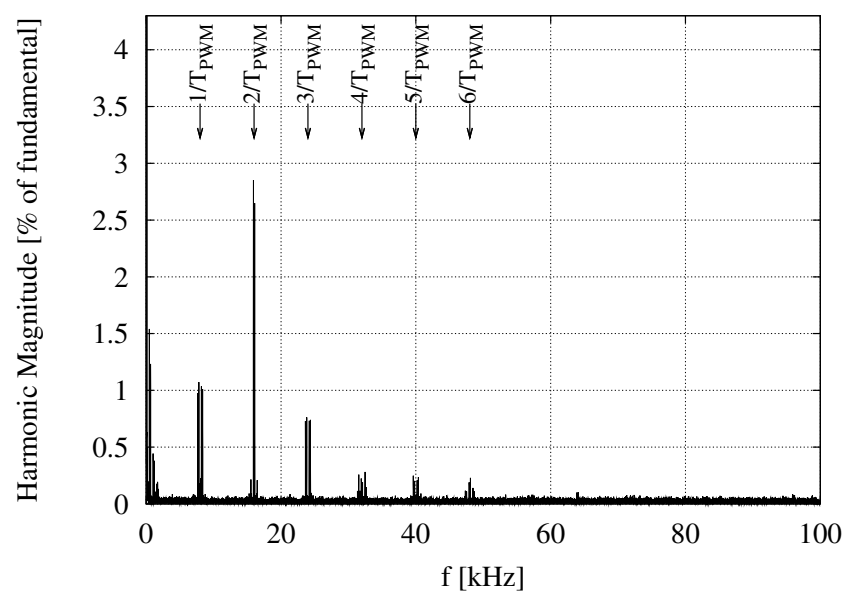

(c) PPC

Fig. 19. Phase Current Spectrum
PPC and with convenient duty cycles, it is possible to exactly reach the reference state vector (Fig. 11) whereas it is not the case with DPC (Fig. 2) and 2PC (Fig. 6). Therefore, PPC leads theoretically to null static errors. However, it can be seen through simulations and experiments that it is not the case. This is due to the fact that, for control schemes, the inverter is considered perfect, which is obviously not the case. Non-idealities such as dead times lead to state vectors that are not exactly the predicted one. With DPC there is only one state change for a sampling period but there is more state changes for other control schemes (up to six for PPC). Therefore, steady state errors are smaller with DPC. This also explains why, with DPC, there is almost no difference between static errors whether the inverter is perfect or not ("Test 1 " and "Test 2" in Fig. 15) while there is a significant difference with $2 \mathrm{PC}$ and PPC.

These static errors can be suppressed by adding a current error corrector [22]. However, the control schemes considered in this paper are equivalent to a torque control so they are generally used inside a speed loop. A well-designed speedcorrector can achieve the desired speed in spite of a static error in the torque loop. Therefore, the measured static errors are not a crucial issue; the torque dynamic and current ripples are more relevant criteria.

Rise times after an inversion of the reference current at the rated value show that the dynamics of the tested control schemes are similar. They are just limited by the DC bus voltage and the electric time constant of the machine.

With DPC, (11) is computed seven times. With 2PC, (11) is computed only two times (for $i=0$ and for the selected configuration) but there are some additional calculations in order to select a configuration, compute $\gamma$ (14) and the leg duty cycles. With PPC the number of step in the algorithm is small but computations are more complicated ((18) and (25)). Finally the computing duration (related to the total amount of calculations) is not very different for the three tested control schemes (Tab.V). These durations are given by the computing unit directly (instructions "RTLIB_TIC_START () " and "RTLIB_TIC_READ ()" of the DSpace C language library). They include the analog to digital conversion (for currents), the angular position measure, computations and the communication with the ControlDesk environment.

To achieve the same stress level in the power switches inside the inverter, the $2 \mathrm{PC}$ algorithm must run at a slower frequency than DPC. PPC must run even slower. By determining more than one inverter configuration during a computation period, 2PC and most of all PPC lead to a reduced real-time constraint for a given switching frequency as they have an equivalent amount of calculations and a larger sampling period. Therefore, PPC can cope with a less powerful DSP than 2PC and DPC. This is a decisive argument in favour of PPC. 
The overall comparison is quite unfavorable to DPC since it leads to the highest real-time constraint and to an unpredictable variable switching frequency. 2PC and PPC allow to have a known constant modulation frequency. Therefore, the switching frequency is known and, for PPC, harmonic rays are well located near multiples of this frequency. Furthermore, PCC leads to the smallest real-time constraint and to slightly reduced current ripples compared to the other tested control schemes even when there are parameter uncertainties.

Evolutions and improvements can be proposed for the tested algorithms. More complex cost functions can be used for DPC. As an example, in [7] an expansion of the cost function is proposed in order to take into account the number of commutations to reduce the stress of power switches. As another example in [35] the filtered error of stator currents is included in the cost function. The current spectrum is then shaped by designing an appropriate filter. For PPC it can be noted that the proposed method to compute duty cycles is presented only for a conventional switching pattern although in [12] it has been applied with another switching pattern (sequence in which a leg does not switch during a modulation period). Another way to improve performances is the computation of duty cycle in order to minimize the current ripple amplitude like in [36].

\section{CONCLUSION}

Three predictive current controls for PMSM and their practical implementation on a DSP have been presented. Detailed comparisons between these control schemes, based on simulation and experimental studies, have been given. Similar dynamic performances are obtained although some improvements can be noted with PPC: largely reduced real-time constraint, constant switching frequency and slightly reduced currents ripples. Also, it can be noted that the detailed method of duty cycle calculation for PPC is easy to implement without additional sine and cosine computations. Further works will be dedicated to the detailed analysis of dead-time effects when PPC is used and to compensation methods.

\section{REFERENCES}

[1] M. P. Kazmierkowski and L. Malesani, "Current control techniques for three-phase voltage-source PWM converters: a survey," IEEE Trans. Ind. Electron., vol. 45, no. 5, pp. 691-703, Oct. 1998.

[2] H. Le-Huy, K. Slimani, and P. Viarouge, "Analysis and implementation of a real-time predictive current controller for permanent-magnet synchronous servo drives," IEEE Trans. Ind. Electron., vol. 41, no. 1, pp. 110-117, Feb. 1994.

[3] P. Cortes, M. Kazmierkowski, R. Kennel, D. Quevedo, and J. Rodriguez, "Predictive control in power electronics and drives," IEEE Trans. Ind. Electron., vol. 55, no. 12, pp. 4312-4324, Dec. 2008.

[4] J. Rodriguez, J. Pontt, C. Silva, M. Salgado, S. Rees, U. Ammann, P. Lezana, R. Huerta, and P. Cortes, "Predictive control of three-phase inverter," Electronics Letters, vol. 40, pp. 561-563, Apr. 29, 2004.

[5] J. Rodriguez, J. Pontt, C. Silva, P. Cortes, U. Ammann, and S. Rees, "Predictive current control of a voltage source inverter" 2004. PESC 04. 2004 IEEE 35th Annual Power Electronics Specialists Conference, vol. 3, pp. 2192-2196, June 20-25, 2004.

[6] J. Rodriguez, J. Pontt, C. A. Silva, P. Correa, P. Lezana, P. Cortes, and U. Ammann, "Predictive current control of a voltage source inverter," IEEE Trans. Ind. Electron., vol. 54, pp. 495-503, Feb. 2007.

[7] R. Vargas, P. Cortes, U. Ammann, J. Rodriguez, and J. Pontt, "Predictive Control of a Three-phase Neutral-point-clamped Inverter," IEEE Trans. Ind. Electron., vol. 54, no. 5, pp. 2697-2705, Oct. 2007.
[8] N. Patin, W. Naouar, E. Monmasson, and J.-P. Louis, "Predictive control of a doubly-fed induction generator connected to an isolated grid," in IEEE IECON 2006 - 32nd Annual Conference on Industrial Electronics, Paris, France, Nov. 2006, pp. 873-878.

[9] P. Cortes, J. Rodriguez, R. Vargas, and U. Ammann, "Cost Functionbased Predictive Control for Power Converters," in IEEE Industrial Electronics, IECON 2006 - 32nd Annual Conference on, Paris, France, Nov. 2006, pp. 2268-2273.

[10] X. Lin-Shi, F. Morel, A. M. Llor, B. Allard, and J. M. Retif, "Implementation of Hybrid Control for Motor Drives," IEEE Trans. Ind. Electron., vol. 54, no. 4, pp. 1946-1952, Aug. 2007.

[11] G. S. Buja and M. P. Kazmierkowski, "Direct torque control of PWM inverter-fed AC motors - a survey," IEEE Trans. Ind. Electron., vol. 51, no. 4, pp. 744-757, Aug. 2004.

[12] F. Morel, "Commandes directes appliquées à une machine synchrone à aimants permanents alimentée par un onduleur triphasé à deux niveaux ou par un convertisseur matriciel triphasé," Ph.D. dissertation, INSA de Lyon, 2007, (in french).

[13] V. Ambrozic, R. Fiser, and D. Nedeljkovic, "Direct current control-a new current regulation principle," IEEE Trans. Power Electron., vol. 18, pp. 495-503, Jan. 2003.

[14] V. Ambrozic, D. Nedeljkovic, and M. Nemec, "Predictive Torque Control of Induction Machines using Immediate Flux Control," in IEEE International Conference on Electric Machines and Drives, 2005, SanAntonio, USA, May 15-18, 2005, pp. 565-571.

[15] V. Ambrozic, G. S. Buja, and R. Menis, "Band-constrained technique for direct torque control of induction motor," IEEE Trans. Ind. Electron., vol. 51, no. 4, pp. 776-784, Aug. 2004.

[16] I. Sarasola, J. Poza, M. Rodríguez, and G. Abad, "Predictive direct torque control for brushless doubly fed machine with reduced torque ripple at constant switching frequency," in IEEE ISIE International Symposium on Industrial Electronics, 2007, June 2007.

[17] M. Pacas and J. Weber, "Predictive direct torque control for the PM synchronous machine," IEEE Trans. Ind. Electron., vol. 52, no. 5, pp. 1350-1356, Oct. 2005.

[18] R. Morales-Caporal and M. Pacas, "A predictive torque control for the synchronous reluctance machine taking into account the magnetic cross saturation," IEEE Trans. Ind. Electron., vol. 54, no. 2, pp. 1161-1167, Apr. 2007.

[19] M. Nemec, D. Nedeljkovic, and V. Ambrozic, "Predictive Torque Control of Induction Machines Using Immediate Flux Control," IEEE Trans. Ind. Electron., vol. 54, no. 4, pp. 2009-2017, Aug. 2007.

[20] H. Abu-Rub, J. Guzinski, Z. Krzeminski, and H. A. Toliyat, "Predictive current control of voltage-source inverters," IEEE Trans. Ind. Electron., vol. 51, no. 3, pp. 585-593, June 2004.

[21] G. Gatto, I. Marongiu, A. Serpi, and A. Perfetto, "Predictive control of synchronous reluctance motor drive," in Proceedings of the IEEE International Symposium on Industrial Electronics, 2007. ISIE 2007, June 2007.

[22] P. Wipasuramonton, Z. Q. Zhu, and D. Howe, "Predictive current control with current-error correction for PM brushless AC drives," IEEE Trans. Ind. Applicat., vol. 42, no. 4, pp. 1071-1079, July/Aug. 2006.

[23] P. Correa, M. Pacas, and J. Rodriguez, "Predictive torque control for inverter-fed induction machines," IEEE Trans. Ind. Electron., vol. 54, no. 2, pp. 1073-1079, Apr. 2007.

[24] O. Kukrer, "Discrete-time current control of voltage-fed three-phase PWM inverters," IEEE Trans. Power Electron., vol. 11, no. 2, pp. 260269, Mar. 1996.

[25] H.-T. Moon, H.-S. Kim, and M.-J. Youn, "A discrete-time predictive current control for PMSM," IEEE Trans. Power Electron., vol. 18, pp. 464-472, Jan. 2003.

[26] A. Linder and R. Kennel, "Model Predictive Control for Electrical Drives,' in Power Electronics Specialists Conference, 2005. PESC '05. IEEE 36th, Recife, Brasil, 2005, pp. 1793-1799.

[27] H. W. van der Broeck, H. C. Skudelny, and G. V. Stanke, "Analysis and realization of a pulsewidth modulator based on voltage space vectors," IEEE Trans. Ind. Applicat., vol. 24, pp. 142-150, Jan./Feb. 1988.

[28] G. Narayanan, H. K. Krishnamurthy, D. Zhao, and R. Ayyanar, "Advanced bus-clamping PWM techniques based on space vector approach," IEEE Trans. Power Electron., vol. 21, no. 4, pp. 974-984, July 2006.

[29] D. Casadei, G. Serra, A. Tani, and L. Zarri, "A Space Vector Modulation Strategy for Matrix Converters Minimizing the RMS Value of the Load Current Ripple," in IEEE IECON 2006 - 32nd Annual Conference on Industrial Electronics, Paris, France, Nov. 2006, pp. 2757-2762.

[30] J. Holtz, "Pulsewidth modulation for electronic power conversion," Proc. IEEE, vol. 82, no. 8, pp. 1194-1214, Aug. 1994. 
[31] A. Kwasinski, P. T. Krein, and P. L. Chapman, "Time domain comparison of pulse-width modulation schemes," IEEE Power Electronics Letters, vol. 1, no. 3, pp. 64-68, Sept. 2003.

[32] A. Qiu, B. Wu, and H. Kojori, "Sensorless control of permanent magnet synchronous motor using extended Kalman filter," in Electrical and Computer Engineering, 2004. Canadian Conference on, vol. 3, Niagara Falls, Ontario, Canada, May 2-5, 2004, pp. 1557-1562.

[33] F. Morel, X. Lin Shi, J.-M. Rétif, B. Allard, and C. Buttay, "Exaustive experimental results available on-line," http://klimt2.insa-lyon.fr/ $\sim$ florent/IEEE_TIE_Annexes.pdf.

[34] U. Amman, R. Vargas, S. Rees, J. Serra, and J. Roth-Stilow, "An analytical approach to steady-state current control properties of power converters featuring discrete-time switching," 2008. PESC 08. 2008 IEEE 39th Annual Power Electronics Specialists Conference, pp. 25352542, June 15-19, 2008.

[35] P. Cortes, J. Rodriguez, D. E. Quevedo, and C. Silva, "Predictive Current Control Strategy With Imposed Load Current Spectrum," IEEE Trans. Power Electron., vol. 23, no. 2, pp. 612-618, Mar. 2008.

[36] D. Casadei, G. Serra, A. Tani, and L. Zarri, "Theoretical and experimental analysis for the RMS current ripple minimization in induction motor drives controlled by SVM technique," IEEE Trans. Ind. Electron., vol. 51, no. 5, pp. 1056-1065, Oct. 2004.

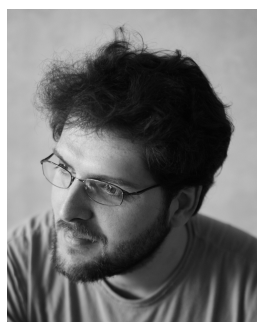

Florent Morel (S'06-M'07) received the Agrégation in electrical engineering from the École Normale Supérieure (ENS), Cachan, France, in 2002. Then he received the M.S. and Ph.D. degrees in electrical engineering from the Institut National de Sciences Appliquées (INSA), Lyon, France, in 2004 and 2007, respectively. His Ph.D. thesis deals with predictive control, permanent magnet synchronous machines, voltage source inverters and matrix converters.

$\mathrm{He}$ is currently with the laboratory AMPERE and the École Centrale, Lyon, France as an associate professor. His research interests include power electronics and electromagnetic compatibility.

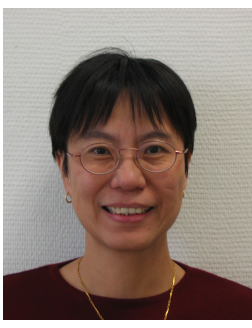

applications.
Xuefang Lin-Shi received the Ph.D degree in applied computer science and automatic in 1992 from INSA Lyon (Institut National des Sciences Appliquees de Lyon), France. Since 1994, she has been an assistant professor at the Electrical Engineering department of INSA Lyon. She joined the Electrical Engineering Center of Lyon (CEGELY) in 1994. She is now with Ampère Laboratory in Lyon, France. Her research interests concern control applied to electrical drives and power electronics power electronic system, notably for high-frequency low power

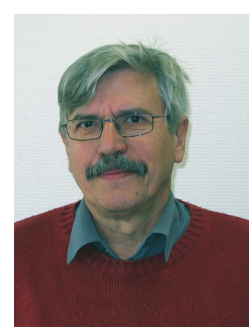

Jean-Marie Rétif received his $\mathrm{PhD}$ in 1979 in tuning control. He was with the laboratory of Energetic and Control of INSA Lyon where he dealt with different subjects such as process control and optimization of solar heating. Since 1979 he has been working on control in the field of electrical engineering at Laboratoire Ampère. Currently, he is interested in the control of hybrid dynamic systems and its applications to power systems.

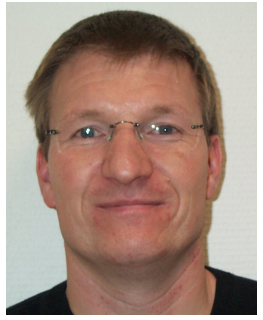

Bruno Allard (M'93-SM'02) is born in 1965. He received the Engineering, M.Sc and Ph.D degrees from Institut National des Sciences Appliquées de Lyon, in Lyon, France respectively in 1988, 1989 and 1992. He joined the Centre de Génie Electrique de Lyon, in Lyon, France, as an Assistant Professor in 1992. He is now a full Professor. His research interests focus the integration of power systems either hybrid or monolithic. It includes power semiconductor device modeling and characterization, power electronic system design, and low-power monolithic converter design. He has leaded numerous industrial and academic projects. $\mathrm{He}$ is the author of more than 50 papers and 80 international conference contributions. He is the head manager of Ampère-lab at INSA-Lyon. He acted as the European Liaison Member in Power Electronics Society Adcom, then has been a member-at-large and contributes currently as Associate-Editor with the Industrial Application Society.

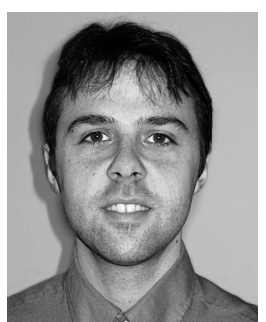

electronics.
Cyril Buttay (S'04, M'06) received the Engineering and $\mathrm{Ph} . \mathrm{D}$. degrees from the "Institut des Sciences Appliquées" (INSA) in Lyon, France, in 2001 and 2004 respectively. He then worked for two years with the Electrical Machines and Drives research team (Sheffield, UK) and the Power Electronics, Machines and Control group (Nottingham, UK) on power electronics packaging.

$\mathrm{He}$ is now a CNRS researcher within the Ampère research lab, in Lyon, where he focusses on packaging solutions for high temperature, $\mathrm{SiC}$-based power 